\title{
BMJ Open Inequalities in realised access to healthcare among recently arrived refugees depending on local access model: study protocol for a quasi- experimental study
}

\author{
Judith Wenner, ${ }^{\oplus 1}$ Kristin Rolke, ${ }^{1}$ Jürgen Breckenkamp, ${ }^{1}$ Odile Sauzet, ${ }^{1}$ \\ Kayvan Bozorgmehr, ${ }^{2,3}$ Oliver Razum ${ }^{1}$
}

To cite: Wenner J, Rolke K, Breckenkamp J, et al. Inequalities in realised access to healthcare among recently arrived refugees depending on local access model: study protocol for a quasiexperimental study. BMJ Open 2019;9:e027357. doi:10.1136/ bmjopen-2018-027357

- Prepublication history for this paper is available online. To view these files please visit the journal online (http://dx.doi. org/10.1136/bmjopen-2018027357)

Received 18 0ctober 2018 Revised 4 March 2019 Accepted 2 May 2019

Check for updates

(c) Author(s) (or their employer(s)) 2019. Re-use permitted under CC BY-NC. No commercial re-use. See rights and permissions. Published by BMJ.

${ }^{1}$ Department of Epidemiology and International Public Health, Bielefeld School of Public Health, Bielefeld, Germany

${ }^{2}$ Department of General Practice and Health Services Research, University Hospital Heidelberg, Heidelberg, Germany ${ }^{3}$ Department of Population Medicine and Health Services Research, Bielefeld School of Public Health, Bielefeld, Germany

Correspondence to

Judith Wenner;

judith.wenner@uni-bielefeld.de

\section{ABSTRACT}

Introduction In many countries, including Germany, newly arriving refugees face specific entitlement restrictions and access barriers to healthcare. While entitlement restrictions apply to all refugees who seek protection in Germany during the first months, the barriers to access depend on the model that the states and the municipalities implement locally. Currently, two different models exist: the healthcare voucher model $(\mathrm{HcV})$ and the electronic health card model (eHC). The aim of the study is to analyse the consequences of these two different access models on newly arrived refugees' realised access to healthcare. Methods and analysis The random assignment of refugees to municipalities allows for a quasi-experimental design by comparing realised access to healthcare among refugees in six municipalities in North Rhine-Westphalia which have implemented $\mathrm{HcV}$ or eHC. We compare realised access to healthcare using ambulatory care sensitive conditions and health expenditure as outcome indicators, and use of emergency care, preventive care, psychotherapeutic or psychiatric care, and of therapeutic devices as process indicators. Results will be adjusted for aggregated information on age, sex, socioeconomic structure of the municipalities and density of general practitioners or specialists.

Ethics and dissemination We cooperated with local welfare offices and the statutory health insurance for data collection. Thereby, we were able to avoid recruiting large numbers of refugee patients immediately after arrival while their access and entitlement to healthcare are restricted. We developed an extensive data protection concept and ensured that all data collected are fully anonymised. Results will be published in peer-reviewed journals and summarised in reports to the funding agency.

\section{INTRODUCTION}

In many countries, newly arriving refugees face specific entitlement restrictions and access barriers to healthcare. ${ }^{2}$ The underlying regulations have been discussed from ethical, human rights and legal perspectives. $^{3-5}$ While we acknowledge the
Strengths and limitations of this study

- Our study comprises a large and diverse sample of refugees during the period of restricted entitlements that are usually excluded from health system research and official health reporting.

- Refugees are randomly assigned to different municipalities, which allows for a quasi-experimental research design.

- Due to selection bias we might underestimate the effect size as municipalities with restrictive refugee health policies are less likely to participate.

- Demographic information is not collected on the individual, but on the municipality level.

importance of these fundamental debates, our study focuses on the actual consequences of these regulations for the use of healthcare among recently arrived refugees. We concentrate on the regulations that apply to refugees during their first years after arrival as we consider this time to be a socially critical period (as defined by Bartley et $a t^{6}$ ), and as such as decisive for the individual's further life course and the development of social and health inequalities.

In the first 15 months after arrival, entitlement to healthcare is restricted and formal access is not equal to that of persons covered via the statutory health insurance. Entitlement is restricted by Articles 4 and 6 of the Asylum Seekers' Benefits Act (AsylbLG). The AsybLG covers the cost of healthcare provision in case of acute illness and pain, pregnancy and birth, as well as for officially recommended vaccination and medically necessary check-ups. Other services, for example diagnoses and treatment of non-acute chronic illness or (long-term) psychotherapy, are only granted on a case-by-case basis. ${ }^{7}$ Among 


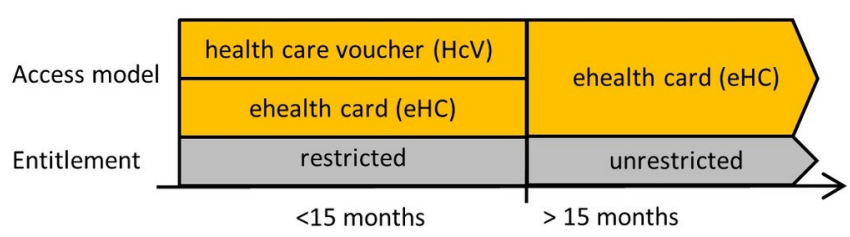

Figure 1 Healthcare for newly arrived refugees in Germany: simplified access model and entitlement in municipalities (own illustration).

persons facing these restrictions, hospitalisations and emergency care use is increased, while numbers of prescriptions and dental visits are decreased, compared with persons insured via the standard statutory health insurance, showing that these legal regulations actually shape patterns of healthcare use. ${ }^{8}$

Besides these entitlement restrictions that apply to all newly arrived refugees-with the exception of unaccompanied minors-the bureaucratic procedures required before healthcare services can be accessed have been identified as barriers to necessary care. ${ }^{9}$ Given that these procedures differ between municipalities and federal states, the actual access also differs. Basically, two different access models exist: the electronic health card model (eHC) and the healthcare voucher model ( $\mathrm{HcV}$ ) (figure 1). The eHC model provides access comparable with that of patients in the statutory health insurance. Refugees receive e-health cards once they are assigned to a municipality. They can directly access healthcare services presenting the card at the hospital or in a doctor's office, but the entitlement restrictions largely remain. The $\mathrm{HcV}$ model constitutes a parallel access model specifically for refugees during the first 15 months. In municipalities using the $\mathrm{HcV}$ model, refugees need to apply for healthcare vouchers at the local welfare authorities before accessing care. These healthcare vouchers are valid usually for 3 months. ${ }^{9-11}$

After 15 months, all refugees receive e-health cards and join a statutory health insurance. The restrictions of Articles 4 and 6 no longer apply (figure 1). If their asylum claims have been approved or they find employment, this happens even earlier. In some cases (eg, when persons have not revealed their identities), the restrictions are extended (Article 2 of AsylbLG).

Each of the 16 federal states in Germany decides on the access model to be implemented. Some federal states have left it to the municipalities to either opt for the $\mathrm{HcV}$ or the eHC model. North Rhine - Westphalia (NRW) is the only federal state in which both models are concurrently in use in a considerable number of municipalities. Refugees in NRW are randomly assigned to municipalities-and thereby to the different access models-after leaving the initial reception centres. Assignment of refugees takes place according to the population size and area size of the municipalities without prior consideration of assumed healthcare needs of the refugees. Members of one family (parents and children) are assigned to the same municipality. Exceptional circumstances-including

\section{MACRO}

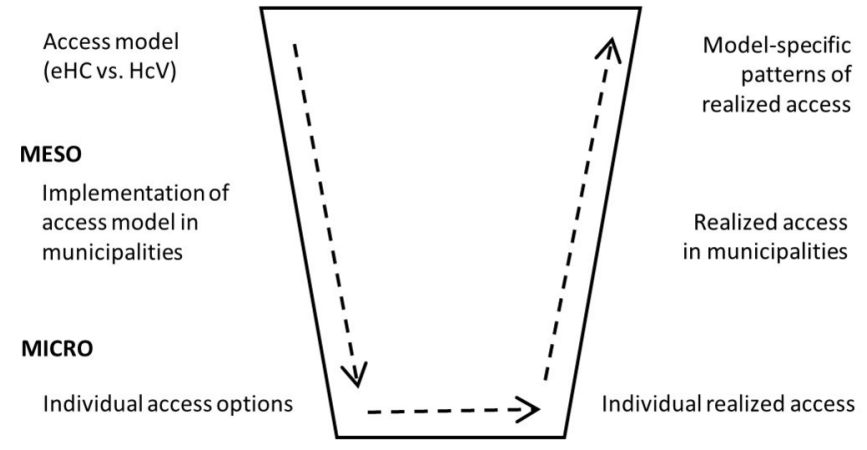

Figure 2 Overall study hypothesis (own illustration). eHC, electronic health card model; HcV, healthcare voucher model.

psychomedical needs-might later lead to reassignment (eg, if treatment is only possible in a certain municipality). ${ }^{12}$

We hypothesise that the choice of the model affects access to healthcare, utilisation and healthcare expenditures. So far, this has hardly been studied. However, available research results suggest that the $\mathrm{HcV}$ model constitutes a barrier to ambulatory healthcare, ${ }^{9}$ leads to higher healthcare expenses, ${ }^{13}$ and might explain-at least partly - the increased use of emergency care among refugees, and the lower utilisation of outpatient healthcare services. ${ }^{14}$ This leads to the overall study hypothesis: the access model (macro-level) and its implementation (meso-level) influence the access to healthcare for refugees living in the respective municipalities (micro-level). As a consequence, we expect to observe different patterns of realised access at the municipality level (meso-level) and between access models (macro-level) (cf, figure 2, based on $\left.\operatorname{ref}^{15}, \mathrm{p} 10\right)$.

\section{METHODS AND ANALYSIS}

\section{Design, setting, participants and sample size}

We here define refugees as all persons who recently migrated to Germany seeking legal protection-irrespective of their legal status and the reasons for seeking protection. Refugees are randomly assigned to municipalities. As municipalities have implemented different access models (eHC or $\mathrm{HcV}$ ), a quasi-experimental study design can be realised.

At the end of 2016, 191312 refugees lived in municipalities in NRW and were entitled to healthcare services according to Articles 4 and 6 of AsylbLG. Of these, 21.6\% (41 348) lived in one of the 20 municipalities using the eHC model at that time. In 2017, of the 122405 recently arrived refugees, $23.3 \%$ lived in one of the meanwhile 24 municipalities using the eHC model. ${ }^{16}$

We calculated the sample size based on the primary outcome (ambulatory care sensitive conditions, ACSC). In a similar study, the incidence rate of ACSC was 38 per 1000 among refugees living in municipalities with eHC. ${ }^{8}$ We found no study investigating the ACSC of refugees 
living in municipalities with $\mathrm{HcV}$. Based on the results from reports and qualitative studies, we estimated an incidence rate of 50 per 1000 . With a predefined power of 0.8 and a significance level of 0.05 , we calculated a sample size of 4750 per group. We decided to include one larger city, one medium-sized city and one smaller city for each group in order to meet the necessary sample size and reflect possible differences between settings. In total, we thus recruited six municipalities. In these municipalities, all newly arrived refugees entitled to healthcare through the local welfare offices are going to be included in the study.

As the number of municipalities with eHC is comparatively small (22 with eHC compared with 374 with $\mathrm{HcV}$ ), recruitment started among the 22 eHC municipalities. Recruitment was realised through the statutory health insurance companies. The municipalities differ in population size and organisational structure (independent city or district-affiliated city). Subsequently, we applied purposive sampling to recruit municipalities using the $\mathrm{HcV}$ model, considering their population size and organisational structure. As we were able to include all refugees entitled to services during the study period, no further sampling was necessary.

Data collection started in June 2018 and will last until the beginning of 2019. Data have to be collected retrospectively, as healthcare providers need several months for controlling and billing. Ultimately, we will include data on healthcare use for seven subsequent quarters (2-2016 until 4-2017).

\section{Variables and data sources}

For municipalities using the HcV model, refugees' demographic data and data on use of healthcare services have to be collected directly at the local welfare office or from the external service providers in case the municipalities have outsourced the verification and payment of invoices. In municipalities which have implemented the eHC model, data have to be collected from the responsible statutory health insurance. ${ }^{17}$

Data include principal and secondary diagnoses (International Classification of Diseases 10th Revision (ICD-10) codes), type of care used (primary, specialist, emergency or hospital care), procedures and prescriptions and date of use (quarterly). Quarterly data on the number of refugees according to age and sex are provided by the health insurances or the welfare offices. These are available as aggregated information only. Similarly, healthcare expenditure is available as aggregated variable only.

\section{Outcome: realised access}

The primary outcome we are interested in is realised access to healthcare. The only available data that might serve as an indicator of access to healthcare are use of healthcare services and related expenditures. Given that expenditures are the direct consequence of use and thus primarily determined by use, we focus here on the relationship between access and use. In line with the 'Behavioral Model of Health Service Use' developed and updated by Ronald M Andersen, ${ }^{18}$ we consider use to be equal to realised access and thereby a suitable proxy for access. The available claims data do not allow for analysis of more complex concepts of access-for example, as the fit between the individuals' and the systems' characteristics. ${ }^{19}$ Use and expenditure are generalised measures that need hypothesis-based concretisation. We developed three subhypotheses on the effects of the $\mathrm{HcV}$ model on use and thereby also on local healthcare expenditure, assuming that the hypothesised effects are absent in municipalities using the eHC model. All three hypotheses thus refer to differences in use and expenditure between refugees in municipalities using health vouchers (exposed) and refugees in municipalities issuing e-health cards (unexposed). For each subhypothesis, we operationalised suitable outcome measures.

\section{Emergency care}

Healthcare vouchers are said to complicate access to care-especially to primary or specialised ambulatory care ${ }^{14}$ The vouchers are valid only for 3 months, they are not always known to the health professionals, and they immediately show that a person has no full entitlement to healthcare. Patients might delay, or refrain from, using ambulatory services to avoid applying for and showing the vouchers. There is no need to present the healthcare voucher for emergency care. ${ }^{90-23}$ As a consequence, we assume a higher use of emergency care services. We will calculate incidence rates of emergency cases (outcome 1) and relative risks for each quarter. If the emergency case led to hospitalisation, only the date of admission will be considered. We count emergency cases (even if a person uses emergency services several times per quarter) and relate the cases to the number of persons eligible to services according to AsylbLG Articles 4 and 6. We will also count the number of individuals who have used emergency services at least once in the quarter. For individual-level regression analysis, a dichotomous outcome variable will be coded containing the information whether or not an individual had used emergency care in the quarter. For ecological regression analysis, quarterly incidence of emergency cases in the six municipalities will serve as outcome variable.

\section{Delayed treatment}

The additional effort needed to access care in municipalities with $\mathrm{HcV}$ model might also lead to delays in treatment. Instead of accessing primary care, patients might delay treatment until hospitalisation is necessary. Hospitalisations that could have been avoided with adequate outpatient care are defined as ambulatory care sensitive hospitalisations (ACSH). Usually, ACSH is identified based on the related diagnoses. Accordingly, ACSC is thus defined as "conditions for which good outpatient care can potentially prevent the need for hospitalization, or for which early intervention can prevent complications 
or more severe disease' (p1). ${ }^{24}$ ACSH is considered to be a valid indicator of access barriers to ambulatory care in general $^{25-28}$ and has also been identified as a useful indicator of access to primary ambulatory care among forced migrants. ${ }^{89}{ }^{30}$ Several different catalogues of ACSC have been developed internationally. Recently, they have been adapted and validated for the German context. ${ }^{31}$ The full list of ACSC comprises 40 diagnosis groups, with 22 being considered as core diagnosis groups. The full list compiled by Sundmacher $e t a l^{32}$ includes 258 ambulatory-sensitive ICD-10 codes. For children, we use a slightly modified list developed by Lichtl et al..$^{30}$ Based on these lists, we define ambulatory care sensitive cases (outcome 2) and calculate incidence rates per quarter in municipalities using the $\mathrm{HcV}$ model and the eHC model (with $\mathrm{n}$ being all refugees entitled to services in the quarter). We will compare incidence rates over time and between municipalities. We will also calculate relative risk comparing the incidence between models. Again, we will calculate incidence rates (counting all cases even if one person has several ACSC diagnosed) and in addition the share of individuals with at least one ACSC per quarter. As described for outcome 1 , we will use a dichotomous outcome variable and the quarterly incidence as outcomes for regression analysis. If the number of cases allows, we will further differentiate between ACSC cases with regular referral and emergency ACSC cases where patients have been hospitalised after visiting or being brought to the emergency department.

\section{Non-urgency of treatment}

The delay in treatment and the increase in emergency care use or hospitalisations might not materialise during the observation period (first 15 months of stay in Germany) as assumed in hypotheses 1 and 2 (above). It may materialise only afterwards, once the entitlement restrictions cease to apply and e-health cards are issued for all. During the observation period, this would still result in a lower use of outpatient cases (primary care) among refugees living in municipalities with a healthcare voucher-especially for deferrable services such as check-ups or prevention. ${ }^{14}$ The participation in medically necessary check-ups ( $Z$ codes according to ICD-10-GM (German Modification)) has been used as outcome measure for access barriers and discrimination related to minority or migration status. ${ }^{22334}$ However, the use of preventive care (outcome 3 ) as outcome is conditioned on the size of the population groups entitled to preventive services (pregnant women, children, elderly) in the available data and the quality of information on age and sex. If information on age and sex is not detailed enough, we will only include the incidence of persons using outpatient care among all people entitled to care in the quarter-also differentiating between ambulatory and specialised care.

In addition to postponing preventive care (which should be guaranteed according to Article 4 of AsylbLG in all municipalities), municipalities using the $\mathrm{HcV}$ model might refuse to refund services as part of the case-by-case review (Article 6 of AsylbLG) referring to the non-urgency of the treatment (Kriterium der Aufschiebbarkeit). The framework agreement on the e-health card abolishes any consideration of non-urgency of treatment. Thus, in municipalities using the e-health cards, most services are granted irrespective of their urgency. However, in municipalities using the $\mathrm{HcV}$ model, urgency of treatment might still be considered. Psychotherapy and therapeutic devices ('Hilfsmittel') have been identified as services for which the consideration of urgency might lead to differences in realised access. ${ }^{35-37}$ We will thus compare psychotherapeutic care cases (outcome 4) and refunded therapeutic devices (outcome 5) between access models. Cases of psychotherapeutic care are defined as visits to specialised doctors (psychiatrists and psychological psychotherapists) and not based on diagnoses. For psychotherapeutic care, repeated visits by the same person in the same quarter will not be counted separately. For therapeutic devices, prescriptions for the same device for the same person in the same quarter will not be counted separately. Incidence rates and relative risk will be calculated for each quarter comparing risks between models and over time.

\section{Outcome: expenditures}

So far, we only referred to the ACSC as outcome indicator and several process indicators related to healthcare use. However, data on healthcare expenditure are available (excluding administrative costs). This allows us to relate our indicators of use to the related healthcare expenditure in the municipalities. We assume the following consequences for per capita expenditure:

\section{Expenditures on emergency care}

In line with the hypothesis on emergency care, the $\mathrm{HcV}$ access model is associated with higher use of emergency care and thereby leads to higher healthcare expenditures for emergency care per capita (per quarter) in municipalities using the $\mathrm{HcV}$ model compared with municipalities with the eHC model.

\section{Expenditures related to delayed treatment}

In line with the hypothesis on delayed treatment, the $\mathrm{HcV}$ access model is associated with higher risk for ACSH. We therefore assume higher healthcare expenditures for inpatient care per capita (per quarter) in municipalities using the $\mathrm{HcV}$ model compared with municipalities with the eHC model.

\section{Expenditures related to the non-urgency of treatment}

The $\mathrm{HcV}$ access model is hypothesised to be associated with lower use of preventive, psychiatric, psychotherapeutic (outpatient) care and therapeutic devices if use of these services is postponed or considered as non-urgent by the municipalities. As a consequence, we expect lower healthcare expenditures for outpatient care per capita (per quarter) in municipalities using the $\mathrm{HcV}$ model compared with municipalities with the eHC model.

Healthcare expenditure per capita and quarter in the municipalities will thus be differentiated according to inpatient, outpatient and emergency care, and interpreted against the backdrop of the results from the analysis of realised access. More detailed analyses of expenditures 
for specific health services will not be feasible as information on expenditures is only available on aggregated level.

Covariates or confounders

The major determinant of healthcare use we are interested in is the access model used in the municipalities. However, healthcare policies and their implementation as locally diverging access models are only one of the many determinants of healthcare use. Andersen ${ }^{18}$ identified several additional determinants of healthcare use, with the health system being just one of them and access models being just one element of the health system. Thus, a much broader approach is needed given that confounding by other determinants of use of healthcare services is probable. We thus adapted Andersen's general model of health service use with regard to our research setting and analyse the availability of data or information for the different determinants (cf, refs ${ }^{1838}$ ).

Table 1 Determinants of healthcare utilisation according to Andersen ${ }^{18}$

\section{Explanation and concretisation (adapted from ref ${ }^{18}$ )}

\section{Availability of information}

\begin{tabular}{|c|c|c|}
\hline \multicolumn{3}{|c|}{ Predisposing characteristics } \\
\hline Demographics & Age and sex. & $\begin{array}{l}\text { Aggregated data available for all municipalities; individual } \\
\text { level data only available from municipalities with eHC. }\end{array}$ \\
\hline Social structure & Socioeconomic status and origin/nationality. & Not available. \\
\hline Health beliefs & $\begin{array}{l}\text { Attitudes, values and knowledge about health or } \\
\text { health services. }\end{array}$ & Not available. \\
\hline
\end{tabular}

Enabling resources
Individual/Family $\quad$ Financial means and health insurances.

Not available; entitlements to benefits according to AsylbLG are need-based, and thus these regulations apply only to people whose financial means are generally limited and who do not have a valid health insurance in Germany (Article 7 of AsylbLG).

\begin{tabular}{|c|c|c|}
\hline Community & $\begin{array}{l}\text { Availability of health personnel and facilities, travel } \\
\text { and waiting time. }\end{array}$ & $\begin{array}{l}\text { Limited availability: density of general practitioners and } \\
\text { specialised doctors. }{ }^{4041}\end{array}$ \\
\hline Social relationships & Social support. & Not available. \\
\hline \multicolumn{3}{|l|}{ Need } \\
\hline Perceived need & Subjective health. & Not available. \\
\hline Evaluated need & $\begin{array}{l}\text { Professional judgements about healthcare needs } \\
\text { (eg, diagnoses). }\end{array}$ & $\begin{array}{l}\text { Only available for those who actually used healthcare } \\
\text { and even among those who used healthcare limited to } \\
\text { the condition for which healthcare was used; the number } \\
\text { of severe cases with annual individual healthcare costs } \\
\text { of more than } € 35000 \text { is known for municipalities due to } \\
\text { state refunding policies. }{ }^{12}\end{array}$ \\
\hline
\end{tabular}

\section{Healthcare system}

$\begin{array}{lll}\text { Policy } & \text { Macro characteristics of the health system not } & \text { With exception of the access model and its } \\ \text { Resources } & \text { further specified by Andersen. } & \text { implementation, this should be the same for all } \\ & & \text { municipalities in NRW. }\end{array}$

Organisation

\section{External environment}

$\begin{array}{lll}\text { Physical } & \text { Natural and built environment. } & \begin{array}{l}\text { Availability very limited: information on types } \\ \text { of accommodation in municipalities (central or } \\ \text { decentralised). }{ }^{16}\end{array} \\ \text { Political } & \text { Political context (global, national, state, local). } & \begin{array}{l}\text { No difference between municipalities for global, national } \\ \text { and state levels; local level: information on population } \\ \text { size, organisational structure (eg, independent city, } \\ \text { county-affiliated) }{ }^{42} \text { and results from local elections as we } \\ \text { as the political party of the ruling major. }\end{array} \\ & \text { Economic structure. } & \begin{array}{l}\text { No difference between municipalities for global, } \\ \text { national and state levels; local level: data available for } \\ \text { municipalities in Germany (unemployment rate, average } \\ \text { household purchasing power, age structure). }{ }^{42}\end{array}\end{array}$

\section{Health practices}

Personal health practices Diet, exercise and self-care (not related to seeking Not available. care).

AsylbLG, Asylum Seekers' Benefits Act; eHC, electronic health card model; NRW, North Rhine-Westphalia. 
Table 1 shows that there are important individual-level determinants of use that we are not able to consider (especially socioeconomic status, health beliefs, individual enabling resources, need and personal health practices). Given that refugees are almost randomly assigned to the municipalities, our study can be considered as a natural experiment or a quasi-experimental study. Under these quasi-experimental conditions, the determinants should be independent of the access model. As a result, confounding by these determinants of use should be minimal. We will still control for significant differences in demographic characteristics that persist despite random assignment, based on the available aggregated data on sex and age. In addition, information on important contextual, health system and community-related determinants is available, as listed in table 1 . This is the case for availability of doctors, and overall sociodemographic, economic and political context. Adjustment for these aspects is thus possible at the municipality level. However, we will be unable to control for confounding by other individual-level determinants, for example health beliefs or needs and clustering by family relations or country of origin. We will acknowledge these limitations when discussing the results.

\section{Planned statistical analysis}

We aim to shed light on the development of health inequalities in the socially critical phase refugees face immediately after arrival in Germany and the importance of the local context in providing access to healthcare. However, we analyse inequalities only in the sense of (descriptive) differences and not in the sense of inequities, which would constitute a separate interpretative step.
Incidence rates and relative risks of all five outcomes will be analysed for seven quarters comparing municipalities with eHC and with HcV. Timing and pathways of care will also be explored. Analysis will be adjusted for aggregated information on age and sex provided by the municipalities. As part of the descriptive analysis, we will also compare healthcare expenditures in the municipalities. Subsequently, we will perform a multivariate regression analysis. As the detailedness of the data is limited (few municipalities and no individual-level data on age and sex), we will explore different possible approaches to statistical analysis and compare the results. In the ecological analysis, we will use general linear regression models with quarterly incidence rates in the six municipalities as outcomes. In the individual-level analysis, we will include each of the outcomes as (dependent) outcome variable, the access model as (independent) exposure variable, and conduct repeated (seven quarters) cross-sectional regression analysis. In both cases, we will include the agesex distribution, socioeconomic and political structure of the community, and density of general and specialised practitioners, respectively, as covariates in the regression models (cf, table 1). Table 2 summarises the most important methodological aspects of this study.

\section{Public and patient involvement}

The quantitative study described here is embedded in a larger mixed-methods project. As part of the project, we have conducted qualitative semistructured interviews (not described in detail here) with refugees and other informants from one of the six municipalities. The perspectives of the interview participants informed the hypotheses and the selection of suitable outcomes. The final results will be made

Table 2 Overview and brief explanation of the methodological approach of the study

\begin{tabular}{ll}
\hline Methods overview & Explanation \\
\hline $\begin{array}{l}\text { Study design } \\
\text { Sample }\end{array}$ & $\begin{array}{l}\text { Quasi-experimental. } \\
\text { Rhine-Westphalia, Germany. }\end{array}$ \\
Study period & 2-2016 to 4-2017. \\
Main hypothesis & $\begin{array}{l}\text { The local access model (HcV vs eHC) and its implementation influences the access to healthcare for } \\
\text { newly arrived refugees, leading to differences in realised access between models. }\end{array}$ \\
Subhypotheses & $\begin{array}{l}\text { 1. Emergency care: using the HcV model leads to higher use of emergency care services compared with } \\
\text { the eHC model. }\end{array}$ \\
& $\begin{array}{l}\text { 2. Delayed treatment: using the HcV model leads to higher rates of ambulatory care sensitive conditions } \\
\text { (ACSC) compared with the eHC model. }\end{array}$ \\
& $\begin{array}{l}\text { 3. Non-urgency of treatment: using the HcV model leads to lower use of (deferrable) outpatient services } \\
\text { compared with the eHC model. }\end{array}$ \\
Quarterly incidence rates (IR) and relative risks (RR) of emergency cases (1), ACSC (2) and use of \\
(deferrable) outpatient services (3-5).
\end{tabular}

eHC, electronic health card model; HcV, healthcare voucher model. 
available to refugee patients through social workers in the six municipalities. As data were collected through local welfare offices and statutory health insurances and not directly from patients, there was no further patient or public involvement in recruitment or conduct of the study.

\section{ETHICS AND DISSEMINATION}

To avoid ethical issues, we cooperated with local welfare offices and the statutory health insurance to collect data on use of healthcare among newly arrived refugees. We ensured that data collection would lead to fully anonymised (and even partly aggregated) data, so there was no need to seek consent from individuals and conduct interviews.

We developed a data protection concept in close cooperation with the data protection officer and our study data trustee. Data will be managed, analysed and stored on encoded offline servers. Ten years after the end of the study, the data trustee will delete the data. When publishing our results, we will adhere to the guidelines of the Strengthening the Reporting of Observational Studies in Epidemiology. ${ }^{39}$ Results will be published in peer-reviewed journals and summarised in reports to the funding agency.

Contributors JW, KR und OR designed the study. JB, OS und KB made substantial contributions to its conception and design. JW drafted the manuscript. KR, JB, OS, $\mathrm{KB}$ und $\mathrm{OR}$ revised the manuscript critically for important intellectual content. All authors read and approved the final manuscript.

Funding The work was supported by the Ministry of Culture and Research of the Federal State of North Rhine-Westphalia (grant number 1704i010). We acknowledge the financial support of the German Research Foundation (DFG) and the Open Access Publication Fund of Bielefeld University for the article processing charge.

Competing interests None declared.

Patient consent for publication Not required.

Ethics approval The study has been positively reviewed by the Ethics Committee and the data protection officer of Bielefeld University (application no 2017-099, 10 May 2017).

Provenance and peer review Not commissioned; externally peer reviewed.

Open access This is an open access article distributed in accordance with the Creative Commons Attribution Non Commercial (CC BY-NC 4.0) license, which permits others to distribute, remix, adapt, build upon this work non-commercially, and license their derivative works on different terms, provided the original work is properly cited, appropriate credit is given, any changes made indicated, and the use is non-commercial. See: http://creativecommons.org/licenses/by-nc/4.0/.

\section{REFERENCES}

1. Norredam M, Mygind A, Krasnik A. Access to health care for asylum seekers in the European Union--a comparative study of country policies. Eur J Public Health 2006;16:285-9.

2. International Organization for Migration (IOM) Regional Office Brussels. Migration Health Division (MHD). Summary Report on the MIPEX Health Strand and Country Reports. Brussels: International Organization for Migration (IOM) Regional Office Brussels, Migration Health Division (MHD), 2016.

3. Eichenhofer E. Gesundheitsleistungen für Flüchtlinge. Zeitschrift für Ausländerr und Ausländerpolitik 2013;33:169-75.

4. Ooms G, Hammonds R. Global constitutionalism, responsibility to protect, and extra-territorial obligations to realize the right to health: time to overcome the double standard (once again). Int $J$ Equity Health 2014;13:68.

5. Wild V. Universal access to health care for migrants: applying cosmopolitanism to the domestic realm. Public Health Ethics 2015;8:162-72.

6. Bartley M, Blane D, Montgomery S. Health and the life course: why safety nets matter. BMJ 1997;314:1194-6.
7. Razum O, Wenner J, Bozorgmehr K. Wenn Zufall über den Zugang zur Gesundheitsversorgung bestimmt: Geflüchtete in Deutschland. Das Gesundheitswes 2016;78:711-4.

8. Bauhoff S, Göpffarth D. Asylum-seekers in Germany differ from regularly insured in their morbidity, utilizations and costs of care. PLoS One 2018;13:1-11.

9. Spura A, Kleinke M, Robra B-P, et al. Wie erleben Asylsuchende den Zugang zu medizinischer Versorgung? Bundesgesundheitsblatt Gesundheitsforschung Gesundheitsschutz 2017;60:462-70.

10. Wächter-Raquet M. Einführung der Gesundheitskarte für Asylsuchende und Flüchtlinge. Der Umsetzungsstand im Überblick der Bundesländer. Gütersloh: Bertelsmann Stiftung, 2016.

11. Behörde für Arbeit Soziales Familie und Integration der Freien und Hansestadt Hamburg. Gesundheitsversorgung Ausländer. Best Practice Beispiele aus Hamburg. Bericht der Fachtagung am 8. Hamburg: Dezember 2014 in der Landesvertretung Hamburg in Berlin, 2014.

12. Nordrhein-Westfalen L. Gesetz über die zuweisung und aufnahme ausländischer flüchtlinge (Flüchtlingsaufnahmegesetz - FlüAG) vom 28. Düsseldorf, 2003.

13. Bozorgmehr K, Razum O. Effect of restricting access to health care on health expenditures among asylum-seekers and refugees: a quasi-experimental study in Germany, 1994-2013. PLoS One 2015;10:e0131483.

14. Claassen $K$, Jäger P. Impact of the introduction of the electronic health insurance card on the use of medical services by asylum seekers in Germany. Int J Environ Res Public Health 2018;15:856.

15. Coleman JS. Foundations of social theory. Cambridge: Harvard University Press, 1990.

16. Landesbetrieb Information und Technik Nordrhein-Westfalen. Empfängerinnen und Empfänger von Asylbewerberleistungen in Nordrhein-Westfalen 2010 bis 2017 (unpublished). Düsseldorf, 2018.

17. Ministerium für Arbeit Gesundheit und Soziales des Landes Nordrhein-Westfalen. Rahmenvereinbarung zur Übernahme der Gesundheitsversorgung für nicht Versicherungspflichtige gegen Kostenerstattung nach § 264 Absatz 1 SGB V in Verbindung mit $\S \S 1,1$ a Asylbewerberleistungsgesetz in Nordrhein-Westfalen. 2015 https://www.mags.nrw/sites/default/files/asset/document/ rahmenvereinbarung_online.pdf (accessed 5 Apr 2018).

18. Andersen RM. Revisiting the behavioral model and access to medical care: does it matter? J Health Soc Behav 1995;36:1-10.

19. Penchansky R, Thomas JW. The concept of access: definition and relationship to consumer satisfaction. Med Care 1981;19:127-40.

20. Bozorgmehr K, Schneider C, Joos S. Equity in access to health care among asylum seekers in Germany: evidence from an exploratory population-based cross-sectional study. BMC Health Serv Res 2015;15:502.

21. Wenner J, Razum O, Schenk L, et al. Gesundheit von Kindern und Jugendlichen aus Familien mit ungesichertem Aufenthaltsstatus im Vergleich zu Kindern mit und ohne Migrationshintergrund: Auswertung der KiGGS-Daten 2003-06. Bundesgesundheitsblatt Gesundheitsforschung Gesundheitsschutz 2016;59:627-35.

22. Gee GC, Ro A, Shariff-Marco S, et al. Racial discrimination and health among Asian Americans: evidence, assessment, and directions for future research. Epidemiol Rev 2009;31:130-51.

23. Zentrale Ethikkommission bei der Bundesärztekammer (ZEKO). Versorgung von nicht regulär krankenversicherten Patienten mit Migrationshintergrund. Dtsch Arzteb/ 2013;110:A899-903.

24. Agency for Healthcare Research and Quality. AHRQ Quality Indicators. Guide to prevention quality indicators: hospital admission for ambulatory care sensitive conditions. Rockville: AHRQ Pub, 2007.

25. Faisst $C$, Sundmacher L. Ambulant-sensitive krankenhausfälle: eine internationale übersicht mit schlussfolgerungen für einen deutschen katalog. Das Gesundheitswes 2014;77:168-77.

26. Ansari Z, Laditka JN, Laditka SB. Access to health care and hospitalization for ambulatory care sensitive conditions. Med Care Res Rev 2006;63:719-41.

27. Basu J, Friedman B, Burstin H. Primary care, HMO enrollment, and hospitalization for ambulatory care sensitive conditions: a new approach. Med Care 2002;40:1260-9.

28. Rosano A, Loha CA, Falvo R, et al. The relationship between avoidable hospitalization and accessibility to primary care: a systematic review. Eur J Public Health 2013;23:356-60.

29. Lichtl C, Gewalt SC, Noest S, et al. Potentially avoidable and ambulatory care sensitive hospitalisations among forced migrants: a protocol for a systematic review and meta-analysis. BMJ Open 2016;6:e012216.

30. Lichtl C, Lutz T, Szecsenyi J, et al. Differences in the prevalence of hospitalizations and utilization of emergency outpatient services for ambulatory care sensitive conditions between asylum-seeking 
children and children of the general population: a cross-sectional medical records study (2015). BMC Health Serv Res 2017;17:1-9.

31. Sundmacher L, Schüttig W, Faisst C. Ein konsentierter deutscher Katalog ambulant-sensitiver Diagnosen. Versorgungsatlas 2015.

32. Sundmacher L, Fischbach D, Schuettig W, et al. Which hospitalisations are ambulatory care-sensitive, to what degree, and how could the rates be reduced? Results of a group consensus study in Germany. Health Policy 2015;119:1415-23.

33. Crawley LM, Ahn DK, Winkleby MA. Perceived medical discrimination and cancer screening behaviors of racial and ethnic minority adults. Cancer Epidemiol Biomarkers Prev 2008;17:1937-44.

34. Trivedi AN, Ayanian JZ. Perceived discrimination and use of preventive health services. J Gen Intern Med 2006;21:553-8.

35. Classen G. Rechtsprechungsübersicht zum Flüchtlingssozialrecht (seit 1993). 2015 http://www.fluechtlingsinfo-berlin.de/fr/ gesetzgebung/Urteile2.pdf (accessed 10 Aug 2018).

36. Ministerium für Arbeit Gesundheit und Soziales des Landes Nordrhein-Westfalen. Rahmenvereinbarung zur Übernahme der Gesundheitsversorgung für nicht Versicherungspflichtige gegen Kostenerstattung nach § 264 Absatz 1 SGB V in Verbindung mit §§ 1,1 a Asylbewerberleistungsgesetz in Nordrhein-Westfalen. Anlage 1. 2015 https://www.mags.nrw/sites/default/files/asset/document/ leistungsumfang_anlage1_online.pdf (accessed 5 Apr 2018).
37. Classen G. Sozialleistungen für migrantinnen und flüchtlinge. Loeper Literatur, Pro Asyl: Karlsruhe:, 2008.

38. Janssen C, Swart E v, Lengerke T. Health Care Utilization in Germany. Theory, Methodology, and Results. New York: Springer New York, 2014.

39. von Elm E, Altman DG, Egger M, et al. The Strengthening the Reporting of Observational Studies in Epidemiology (STROBE) statement: guidelines for reporting observational studies. PLOS Med 2007;4:e296.

40. Schulz M, Schulz M, Bätzing-Feigenbaum J, et al. Vertragsärzte und -psychotherapeuten je 100.000 Einwohner nach Bedarfsplanungsfachgebieten und -regionen im Jahr 2013. Versorgungsatlas-Bericht Nr. 15/02. Berlin: Zentralinstitut für die kassenärztliche Versorgung in Deutschland, 2015.

41. Sundmacher L, Busse R. Der Einfluss der Ärztedichte auf ambulantsensitive Krankenhausfälle. In: Klauber J, Geraedts M, Friedrich J, eds. Krankenhaus-report 2012. Stuttgart: Schattauer-Verlag, 2012:183-202.

42. Bertelsmann Stiftung. Wegweiser kommune. $2018 \mathrm{https} / / / \mathrm{www}$. wegweiser-kommune.de/impressum (accessed 6 Apr 2018).

43. Landeswahlleiter des Landes NRW. Wahlergebnisse in NRW. Kommunalwahlen 2014. 2014 https://www.wahlergebnisse.nrw.de/ kommunalwahlen/2014/index.html (accessed 5 Apr 2018). 